\title{
Relationship between antibodies to hepatitis C virus core +1 protein and treatment outcome
}

\author{
Theodora Mylopoulou a , Vasileios Papadopoulos ${ }^{b}$, Katerina Kasselac, loannis Karakasiliotis ${ }^{d}$, \\ Fani Souvalidou ${ }^{\mathrm{e}}$, Panagiotis Mimidise, Stavroula Veletza ${ }^{\mathrm{d}}$, Penelope Mavromarace, Konstantinos Mimidis ${ }^{\mathrm{a}}$ \\ Democritus University of Thrace, Alexandroupolis; ENARGEIA Medical Ltd., Xanthi; Hellenic Pasteur Institute, \\ Athens, Greece
}

\begin{abstract}
Background It has been suggested that hepatitis C virus (HCV) core +1 protein plays a crucial role in the viral life cycle, potentially affecting liver cirrhosis and the development of hepatocellular carcinoma.

Methods To investigate its relationship with the outcome of HCV standard combination therapy with peginterferon- $\alpha$ plus ribavirin, we screened 139 consecutive HCV patients (119 with chronic $\mathrm{HCV}$ infection and 20 who spontaneously cleared HCV) for the presence of anti-core +1 antibodies (Abs). In addition, liver fibrosis was determined by FibroScan in all but one patients.

Results Twenty-nine patients were cirrhotic (stiffness $>12.5 \mathrm{kPa}, \mathrm{F} 4$ METAVIR), all of them with mild liver cirrhosis (Child-Pugh score A). Eighty-six of 139 patients were treatment-experienced with standard combination therapy. Fifty of them had achieved a sustained virological response, while 36 were non-responders. The prevalence of anti-core +1 Abs in patients with chronic HCV infection was $22.69 \%$ (27/119 patients): $18 \%$ (9/50 patients) in responders and $36.11 \%$ (13/36 patients) in non-responders $(\mathrm{P}=0.050)$. Five $(17.24 \%)$ of the 29 cirrhotic patients and $22(24.72 \%)$ of the 89 non-cirrhotic patients were positive for anti-core+1 Abs $(\mathrm{P}=0.405)$. Furthermore, the presence of anti-core +1 Abs correlated with the poor response interleukin (IL) $28 \mathrm{~B}$ genotype TT $(\mathrm{P}=0.040)$. No correlation between spontaneous clearance and anti-core $+1 \mathrm{Abs}$ was observed $(\mathrm{P}=0.088)$.

Conclusion The presence of anti-core +1 Abs might be correlated with the poor response IL28B TT genotype and may negatively affect the outcome of standard combination treatments in HCV patients, suggesting that core +1 may play a biological role in the course of HCV infection.
\end{abstract}

Keywords Core+ $1 /$ ARF protein, hepatitis C treatment, IL28B, IFN $\lambda 4$, prognostic factors for HCV treatment

Ann Gastroenterol 2018; 31 (5): 1-5

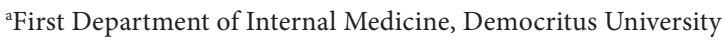
of Thrace, Alexandroupolis (Theodora Mylopoulou, Konstantinos

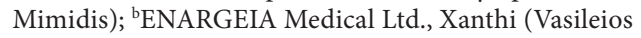
Papadopoulos); 'Laboratory of Molecular Virology, Hellenic Pasteur Institute, Athens (Katerina Kassela, Penelope Mavromara); ${ }^{\mathrm{d}}$ Laboratory of Medical Biology, Department of Medicine, Democritus University of Thrace, Alexandroupolis (Ioannis Karakasiliotis,


Democritus University of Thrace, Alexandroupolis (Fani Souvalidou, Panagiotis Mimidis, Penelope Mavromara), Greece

Conflict of Interest: None

Correspondence to: Konstantinos Mimidis, e-mail: kostasmimidis@ hotmail.com

Received 7 March 2018; accepted 1 June 2018; published online 13 July 2018

DOI: https://doi.org/10.20524/aog.2018.0290

\section{Introduction}

Hepatitis $\mathrm{C}$ virus (HCV) constitutes an infection of global importance, affecting all countries and creating a major global health problem that requires widespread active interventions for its prevention and control [1]. About 71 million people are chronically infected and more than 400,000 people die every year from HCV-related liver diseases [2]. Eighty percent of acute HCV cases progress to chronic infection, which may lead to liver fibrosis, cirrhosis and hepatocellular carcinoma [3]. Twenty-two percent of new cases of liver cancer that occur each year are attributable to HCV infection [4].

HCV treatment with the standard combination of pegylated interferon- $\alpha$ (PegIFN- $\alpha$ ) plus ribavirin has an estimated success rate of $50 \%$ for genotype 1 and about $80 \%$ for genotypes 2 and $3[5,6]$. The use of direct antiviral agents has significantly greater effectiveness; nevertheless, their high cost inevitably limits their 
global use. Thus, studies of potential prognostic factors for the outcomes of classical therapy are still considered useful.

Recently, host-related prognostic factors have been described [7]. Patients carrying the good response rs12979860 C/C interleukin (IL) 28B genotype have been reported to present a two- to threefold higher rate of sustained virological response (SVR) compared to patients with the poor response genotypes rs 12979860 single nucleotide polymorphism $\mathrm{C} / \mathrm{T}$ and $\mathrm{T} / \mathrm{T}[8,9]$. Additionally, an IFN $\lambda$ dinucleotide variant (ss469415590) was studied [10]. Instead of TT, which is the "normal" genotype, the $\Delta \mathrm{G}$ genotype leads to a novel gene product called IFN $\lambda 4$, which seems to impair the clearance of $\mathrm{HCV}$ infection and the response to IFN- $\alpha$ therapy $[11,12]$.

Recently, the presence of antibodies (Abs) against a new viral protein, called core +1 /alternative reading frame (ARF), has been described. Core +1 protein is synthesized by a functional alternative open reading frame within the core genomic region, in the +1 reading frame $[13,14]$; the protein is conserved in all HCV genotypes $[15,16]$ and its biological role remains elusive. Several studies suggest that core +1 protein has a possible role in the HCV life cycle $[17,18]$. Furthermore, Miladi et al, proposed a correlation between core +1 protein and the last stages of liver steatosis [19], while Dalagiorgou et al inferred a possible association between core +1 protein and the development of hepatocellular carcinoma $[16,18,20]$.

In the present study, aiming to further unravel the biological role of core +1 protein, we investigated its potential relationship with the outcome of HCV standard combination therapy, as well as with other known host prognostic factors.

\section{Patients and methods}

\section{Patients}

A group of 139 consecutive patients with positive anti-HCV antibody (91 men and 48 women, aged 20-92 years) from the University Hospital of Alexandroupolis, Greece, gave their informed consent to join the study. Of these, 119 suffered from chronic HCV infection, while 20 had spontaneously cleared $\mathrm{HCV}$. All patients were screened for the presence of anti-core +1 Abs using the ELISA method. Liver fibrosis was determined in all but one patient (who had an excessively high body mass index) by FibroScan. Twenty-nine patients were cirrhotic (stiffness $>12.5 \mathrm{kPa}$, F4 METAVIR); all of them exhibited mild liver cirrhosis (Child-Pugh score A, mean model for end-stage liver disease [MELD] score 8.17). Thirty-three patients were not eligible to receive treatment. Eighty-six of 119 patients had been administered treatment with standard combination therapy (PegIFN- $\alpha$ and ribavirin). Fifty of them had achieved a SVR, while 36 were non-responders (Fig. 1).

\section{Detection of anti-core+1 Abs}

The expression and purification of core +1 protein has been previously described in a previous publication by our group [21]. For the detection of anti-core +1 Abs we performed ELISA, also based on our previous experience [21]. In short, microplate wells were coated with $100 \mu \mathrm{L}$ of a $1 \mu \mathrm{g} \mathrm{mL}^{-1}$ solution of core +1 antigen in $50 \mathrm{mM}$ sodium carbonate $(\mathrm{pH}$ 9.6) overnight at $4^{\circ} \mathrm{C}$. Next, the wells were washed with washing buffer $(0.1 \%[\mathrm{v} / \mathrm{v}]$ Tween-20 in phosphate buffered saline $[\mathrm{PBS}]+1 \%[\mathrm{w} / \mathrm{v}]$ non-fat dried milk) and blocked with PBST $(0.1 \%[\mathrm{v} / \mathrm{v}]$ Tween-20 in PBS) containing $5 \%(\mathrm{w} / \mathrm{v})$ milk for $1 \mathrm{~h}$ at $37^{\circ} \mathrm{C}$. The wells were washed three times with washing buffer, after which $100 \mu \mathrm{L}$ of serum diluted to 1:200 in washing buffer was added in triplicate wells and the plates were incubated overnight at $4^{\circ} \mathrm{C}$. After incubation, the wells were washed three times with washing buffer and then incubated with $100 \mu \mathrm{L}$ of peroxidase-conjugated rabbit anti-human IgG antibody (Dako) at a dilution of 1:4000 (in washing buffer) for $1 \mathrm{~h}$ at $37^{\circ} \mathrm{C}$. After three more washes with washing buffer and two with PBST, the reaction was developed by adding $100 \mu \mathrm{L}$ tetramethyl benzidine substrate (TMB substrate kit; Thermo Scientific) and incubating the plate for $10 \mathrm{~min}$ at room temperature in the dark. The peroxidase reaction was stopped by adding $100 \mu \mathrm{L}$ of $2 \mathrm{~N} \mathrm{H}_{2} \mathrm{SO}_{4}$ and the absorbance was measured at $450 \mathrm{~nm}$ with a microplate reader (Bio-Rad). The cutoff value was determined as the mean optical density of the 51 healthy blood donors' serum plus two standard deviations. Serum samples were considered as positive for anti-core $+1 \mathrm{Abs}$ when the absorbance measurement was above the cutoff value.

\section{Statistical analysis}

The chi-square test was used for comparisons between two or more binary or categorical variables. When two or more expected values were less than 5, Fisher's exact test was preferred. Student's $t$-test was used for comparisons between quantitative variables. Differences between distributions were checked using Levene's test. SPSS 20.0 software was generally used. For Fisher's exact test the statistical tool freely available at http://www.quantitativeskills.com/sisa/statistics/fiveby2.htm and hosted at http://www.statpages.org was preferred. The level of statistical significance was set to $\mathrm{P}<0.05$. In cases where a value $0.1 \leq \mathrm{P} \leq 0.05$ was detected, further studies were suggested. All mean values are accompanied by their standard errors (SE) and are expressed with at least two significant digits.

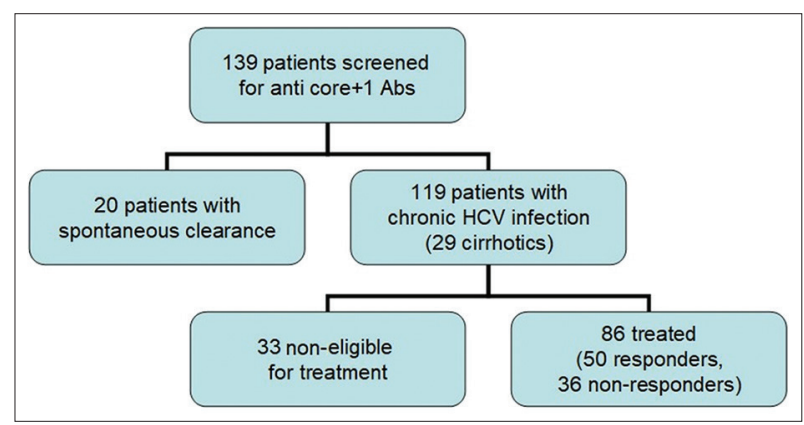

Figure 1 Flowchart illustrating the patient population Abs, antibodies; $H C V$, hepatitis $C$ virus 


\section{Results}

From the initial group of 139 patients, 20 presented spontaneous HCV clearance. Among the remaining 119, the prevalence of HCV genotypes was as follows: genotype 1, 44.54\%; genotype 2, 13.45\%; genotype 3, 28.57\%; and genotype $4,5.04 \%$. HCV genotype was not available in $8.4 \%$ of patients.

Anti-core +1 Abs were measured in all 139 patients. The prevalence of anti-core +1 Abs in patients with chronic $\mathrm{HCV}$ infection (HCV-RNA positive) was 22.69\% (27/119 patients): $24.53 \%$ in genotype $1,31.25 \%$ in genotype $2,17.65 \%$ in genotype 3 and $16.67 \%$ in genotype 4 . All data are presented in detail in Table 1. In addition, we assessed the association between the presence of anti-core $+1 \mathrm{Abs}$ and treatment outcome, cirrhosis, IL28B and IFN $\lambda 4$ polymorphisms, and spontaneous clearance of $\mathrm{HCV}$.

\section{Comparison between specific anti-core+1 Abs and treatment outcome}

Anti-core +1 Abs were available in all 86 treated patients. Fifty of them achieved SVR (responders), while 36 were non-responders. The prevalence of anti-core +1 was $18 \%$ (9/50 patients) in responders and $36.11 \%$ (13/36 patients) in non-responders. Using Fisher's exact test, a level of statistical significance was observed between the presence of anti-core +1 Abs and non-response to treatment $(\mathrm{P}=0.050)$ (Table 2).

\section{Prevalence of specific anti-core+1 Abs in HCV-cirrhotic patients}

Twenty-nine of our patients were cirrhotic (Child-Pugh A, mean MELD score 8.17 ). Five (17.24\%) of the 29 cirrhotic patients were positive for anti-core+1 Abs while 24 (82.76\%) were negative. Twenty-two $(24.72 \%)$ of the 89 non-cirrhotic patients were positive for anti-core+1 Abs while 67 (75.28\%) were negative. Comparison using the chi-square test did not reveal any level of statistical significance (Table 3).

\section{Comparison between anti-core $+1 \mathrm{Abs}$ and host prognostic factors of treatment outcome}

Using the chi-square and Fisher's exact test in our sample, a statistically significant relationship between anti-core $+1 \mathrm{Abs}$ and IL28B genotypes was confirmed. The presence of Abs correlated with the poor response IL28B genotype TT $(\mathrm{P}=0.040)$ (Table 4). No association was found between the presence of anti-core $+1 \mathrm{Abs}$ and the "not-encouraging" IFN $\lambda 4$ genotype $\Delta \mathrm{G} / \Delta \mathrm{G}(\mathrm{P}=0.090)$ (Table 5).

\section{Comparison between specificanti-core+1 Abs and spontaneous clearance of $\mathrm{HCV}$}

Twenty of our 139 patients, 15 men and 5 women, aged 33-72 years, had spontaneously cleared HCV. Eight (40\%) of them were positive for anti-core +1 Abs, while 12 (60\%) were negative. No relationship was observed between the presence of $\mathrm{Abs}$ for the $\mathrm{HCV}$ core +1 protein and the spontaneous clearance of the virus ( $\mathrm{P}=0.088$ by Fisher's exact test) (Table 6$)$.

\section{Discussion}

In order to contribute to the elucidation of the biological role of core +1 protein, we investigated possible associations

Table 1 Characteristics of anti-core +1 Abs positive/negative patients

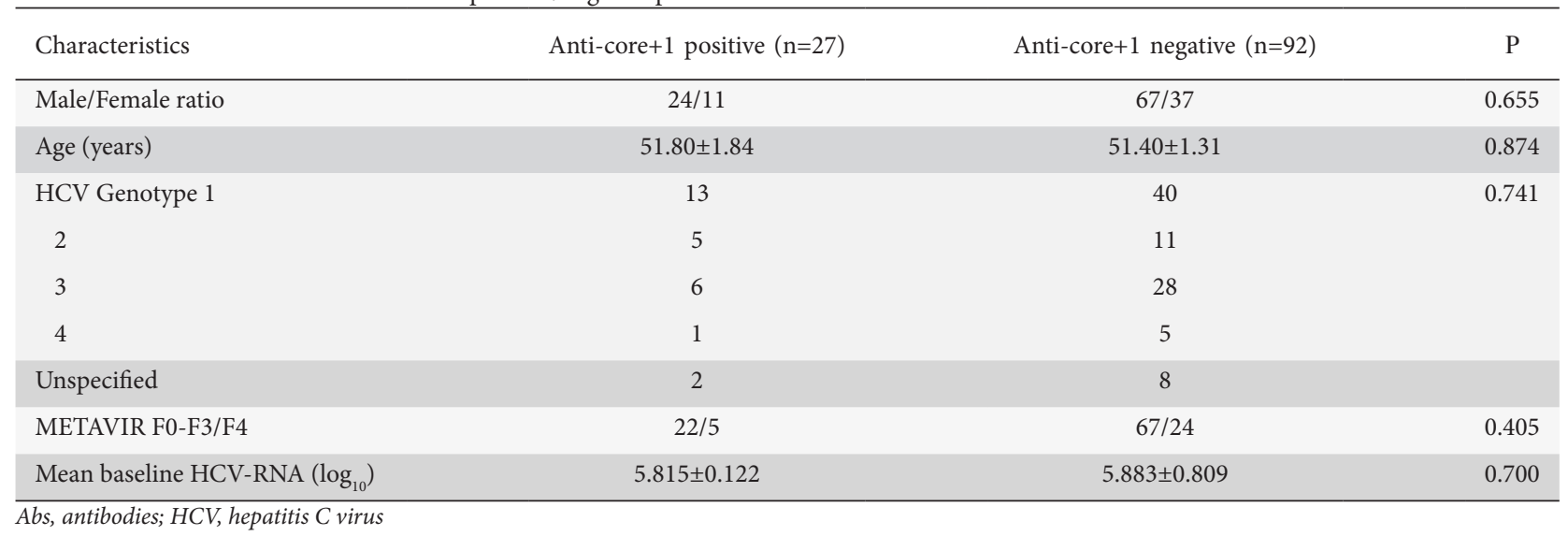

Table 2 Comparison between anti-core +1 antibodies (Abs) and treatment outcome (number of cirrhotic patients in parentheses)

\begin{tabular}{lccc}
\hline Anti-core+1 Abs & Non-responders & Responders & Total \\
\hline Negative & $23(10)$ & $41(1)$ & 64 \\
Positive & $13(3)$ & $9(0)$ & 22 \\
Total & 36 & 50 & 86 \\
\hline * & & & 0.050 \\
\hline
\end{tabular}

${ }^{*}$ Using Fisher's exact test $P=0.050$ 
of anti-core+1 Abs with treatment outcome and known host prognostic factors, such as liver cirrhosis and genetic variations of IL28B and IFN $\lambda 4$. The prevalence of anticore +1 Abs in our study was $22.69 \%$. This finding is consistent with a report by Karamitros et al [22]. However, a higher prevalence was noticed in other studies [23-25]; these results could be attributed to the fact that ELISA tests were performed using $\mathrm{F}$ protein (core +1 protein, which shares the first ten amino acids with core protein) [25]. In contrast, we used a core +1 protein lacking amino acid sequences upstream of the core codon 14 [21]. According to Karamitros et al, anti-core +1 Abs were persistently present

Table 3 Comparison between anti-core +1 antibodies (Abs) and liver cirrhosis

\begin{tabular}{lcccc}
\hline $\begin{array}{l}\text { Anti-core }+1 \\
\text { Abs }\end{array}$ & $\begin{array}{c}\text { Non-cirrhotic } \\
\text { patients }\end{array}$ & $\begin{array}{c}\text { Cirrhotic } \\
\text { patients }\end{array}$ & Total & $P$ \\
\hline Negative & 67 & 24 & 91 & \\
Positive & 22 & 5 & 27 & 0.405 \\
Total & 89 & 29 & 18 & \\
\hline
\end{tabular}

Table 4 Comparison between anti-core +1 antibodies (Abs) and interleukin (IL) 28B genotypes

\begin{tabular}{lccccc}
\hline \multirow{2}{*}{ Anti-core+1 Abs } & \multicolumn{4}{c}{ IL28B genotypes } & \multirow{2}{*}{$P$} \\
\cline { 2 - 5 } & CC & CT & TT & Total & \\
\hline Negative & 20 & 36 & 3 & 59 & \\
Positive & 8 & 11 & 6 & 25 & 0.040 \\
Total & 28 & 47 & 9 & 84 & \\
\hline
\end{tabular}

${ }^{*}$ Using Fisher's exact test mid- $P=0.040$

Table 5 Comparison between anti-core +1 antibodies (Abs) and interferon (IFN) $\lambda 4$ genotypes

\begin{tabular}{|c|c|c|c|c|c|}
\hline \multirow[t]{2}{*}{ Anti-core +1 Abs } & \multicolumn{4}{|c|}{ IFN $\lambda 4$ genotypes } & \multirow[t]{2}{*}{$P$} \\
\hline & $\mathrm{TT} / \mathrm{TT}$ & $\Delta \mathrm{G} / \mathrm{TT}$ & $\Delta \mathrm{G} / \Delta \mathrm{G}$ & Total & \\
\hline Negative & 17 & 20 & 2 & 39 & \\
\hline Positive & 5 & 6 & 4 & 15 & 0.090 \\
\hline Total & 22 & 26 & 6 & 54 & \\
\hline
\end{tabular}

${ }^{*}$ Using Fisher's exact test mid- $P=0.090$ during treatment and were linked to elevated levels of HCVRNA at baseline [22]. However, like others [23,24,26], we were unable to confirm the latter (Table 1). Moreover, we failed to correlate anti-core +1 Abs with $\mathrm{HCV}$ genotype; this finding is in keeping with previous reports [22-25]. Finally, no correlation was observed with spontaneous clearance, although the relatively limited size of our sample raises a need for further investigation.

In our group, the largest ever studied, the presence of anticore +1 Abs was found to be negatively correlated with the response to standard combination therapy. Our results are consistent with those of Gao et al [24] who analyzed a group of 72 Chinese patients and observed a lower prevalence of anti-core $+1 \mathrm{Abs}$ in those who achieved SVR. In contrast, Bain et al [26], followed by Cohen et al [23], did not find any correlation; however, both studies were limited by their small size ( $n=36$ and $n=27$, respectively).

In the present study, we firstly describe an association of anti-core +1 Abs with the IL28B TT genotype. These results are consistent with the already known negative correlation of the IL28B TT genotype with SVR in response to standard combination therapy [7-9,27-30]. However, an association with the "not-so-encouraging" IFN $\lambda 4 \Delta \mathrm{G} / \Delta \mathrm{G}$ genotype [10-12,31] was not documented.

In a previous study, Ajorloo et al reported a $100 \%$ presence of anti-core $+1 \mathrm{Abs}$ in cirrhotics and $80 \%$ in patients without cirrhosis [32]. In contrast, only $17.24 \%$ of our cirrhotic patients were positive for anti-core +1 Abs. The discrepancy in the outcome may be attributed to use of the abovementioned $\mathrm{F}$ protein by Ajorloo's group [21,32]. Moreover, Branch et al [18] and Miladi et al [19], as well as our group [21], reported an association of anti-core +1 Abs with advanced stages of cirrhosis. In the present study, no correlation between anticore $+1 \mathrm{Abs}$ and liver cirrhosis emerged. However, all cirrhotic patients in the present study suffered from mild disease (ChildPugh A, MELD score 8.17), whereas previous studies included only cirrhotic patients with advanced stages of the disease, pre-transplant candidates and patients with hepatocellular carcinoma.

In conclusion, the presence of anti-core $+1 \mathrm{Abs}$ is related to bad prognostic host factors and a poor response to standard combination treatment in $\mathrm{HCV}$ patients. These data suggest that core +1 may play a biological role in the course of $\mathrm{HCV}$ infection.

Table 6 Comparison between anti-core +1 antibodies (Abs) and spontaneous clearance

\begin{tabular}{lcccc}
\hline Anti-core +1 Abs & HCV-RNA positive & Spontaneous clearance of HCV & Total & P \\
\hline Negative & 92 & 12 & 35 & 0.088 \\
Positive & 27 & 8 & 139 & \\
Total & 119 & 20 & \\
${ }^{*}$ Using Fisher's exact test $P=0.088$ & & & \\
HCV , hepatitis C virus & &
\end{tabular}




\section{Summary Box}

\section{What is already known:}

- Anti-core+1/alternative reading frame (ARF) antibodies (Abs) are present in patients chronically infected with hepatitis $\mathrm{C}$ virus (HCV)

- A higher prevalence of anti-core+1/ARF is observed in advanced cirrhosis and hepatocellular carcinoma

\section{What the new findings are:}

- Anti-core+1 Abs are related to a poor response to standard combination treatment in HCV patients

- Anti-core+1 Abs correlate with bad prognostic host factors

\section{References}

1. Lavanchy D. Evolving epidemiology of hepatitis C virus. Clin Microbiol Infect 2011;17:107-115.

2. World Health Organization. Global Hepatitis report 2017, Geneva, Switzerland 2017.

3. Lauer GM, Walker BD. Hepatitis C virus infection. $N$ Engl J Med 2001;345:41-52.

4. World Health Organization. World Health Report, Geneva, Switzerland 1996.

5. Schalm SW, Weiland O, Hansen BE, et al. Interferon-ribavirin for chronic hepatitis $\mathrm{C}$ with and without cirrhosis: analysis of individual patient data of six controlled trials. Eurohep Study Group for Viral Hepatitis. Gastroenterology 1999;117:408-413.

6. Feld JJ, Hoofnagle JH. Mechanism of action of interferon and ribavirin in treatment of hepatitis C. Nature 2005;436:967-972.

7. Ge D, Fellay J, Thompson AJ, et al. Genetic variation in IL28B predicts hepatitis $\mathrm{C}$ treatment-induced viral clearance. Nature 2009;461:399-401.

8. Chen Y, Xu HX, Wang LJ, Liu XX, Mahato RI, Zhao YR. Metaanalysis: IL28B polymorphisms predict sustained viral response in HCV patients treated with pegylated interferon- $\alpha$ and ribavirin. Aliment Pharmacol Ther 2012;36:91-103.

9. Thompson AJ, Muir AJ, Sulkowski MS, et al. Interleukin 28B polymorphism improves viral kinetics and is the strongest pretreatment predictor of sustained virologic response in genotype 1 hepatitis C virus. Gastroenterology 2010;139:120-129.e18.

10. Prokunina-Olsson L, Muchmore B, Tang W, et al. A variant upstream of IFNL3 (IL28B) creating a new interferon gene IFNL4 is associated with impaired clearance of hepatitis C virus. Nat Genet 2013;45:164-171.

11. Booth D, George J. Loss of function of the new interferon IFN- $\lambda 4$ may confer protection from hepatitis C. Nat Genet 2013;45:119-120.

12. Urban T, Charlton MR, Goldstein DB. Introduction to the genetics and biology of interleukin-28B. Hepatology 2012;56:361-366.

13. Xu Z, Choi J, Yen TS, et al. Synthesis of a novel hepatitis C virus protein by ribosomal frameshift. EMBO J 2001;20:3840-3848.

14. Varaklioti A, Vassilaki N, Georgopoulou U, Mavromara P. Alternate translation occurs within the core coding region of the hepatitis $\mathrm{C}$ viral genome. J Biol Chem 2002;277:17713-17721.
15. Branch AD, Stump DD, Gutierrez JA, Eng F, Walewski JL. The hepatitis $C$ virus alternate reading frame (ARF) and its family of novel products: the alternate reading frame protein/F-protein, the double-frameshift protein, and others. Semin Liver Dis 2005;25:105-117.

16. Vassilaki N, Mavromara P. The HCV ARFP/F/core+1 protein: production and functional analysis of an unconventional viral product. IUBMB Life 2009;61:739-752.

17. Xu Z, Choi J, Lu W, Ou JH. Hepatitis C virus f protein is a shortlived protein associated with the endoplasmic reticulum. $J$ Virol 2003;77:1578-1583.

18. Branch AD, Walewski JL, Gutierrez JA, et al. HCV alternative reading frame proteins (ARFPs) may be virulence factors that help the virus survive adverse conditions. Hepatology 2003;38:468A-469A.

19. Miladi A, Lavergne JP, Hezode C, Dhumeaux D, Penin F, Pawlotsky JM. Prevalence of anti-HCV F (frameshift) protein antibodies in patients with various forms of HCV infection and the putative physiological role of $\mathrm{F}$ protein. $11^{\text {th }}$ International Symposium on Hepatitis C Virus and Related Viruses 2004:238.

20. Dalagiorgou G, Vassilaki N, Foka P, et al. High levels of HCV core +1 antibodies in $\mathrm{HCV}$ patients with hepatocellular carcinoma. J Gen Virol 2011;92:1343-1351.

21. Kassela K, Karakasiliotis I, Charpantidis S, et al. High prevalence of antibodies to core+1/ARF protein in HCV-infected patients with advanced cirrhosis. J Gen Virol 2017;98:1713-1719.

22. Karamitros T, Kakkanas A, Katsoulidou A, et al. Detection of specific antibodies to $\mathrm{HCV}-\mathrm{ARF} / \mathrm{CORE}+1$ protein in patients treated with pegylated interferon plus ribavirin. J Viral Hepat 2012;19:182-188.

23. Cohen M, Bachmatov L, Ben-Ari Z, Rotman Y, Tur-Kaspa R, Zemel R. Development of specific antibodies to an ARF protein in treated patients with chronic HCV infection. Dig Dis Sci 2007;52:2427-2432.

24. Gao DY, Zhang XX, Hou G, et al. Assessment of specific antibodies to $\mathrm{F}$ protein in serum samples from Chinese hepatitis C patients treated with interferon plus ribavarin. J Clin Microbiol 2008;46:3746-3751.

25. Komurian-Pradel F, Rajoharison A, Berland JL, et al. Antigenic relevance of $\mathrm{F}$ protein in chronic hepatitis $\mathrm{C}$ virus infection. Hepatology 2004;40:900-909.

26. Bain C, Parroche P, Lavergne JP, et al. Memory T-cell-mediated immune responses specific to an alternative core protein in hepatitis C virus infection. J Virol 2004;78:10460-10469.

27. Peiffer KH, Sommer L, Susser S, et al. Interferon lambda 4 genotypes and resistance-associated variants in patients infected with hepatitis C virus genotypes 1 and 3. Hepatology 2016;63:63-73.

28. Tanaka Y, Nishida N, Sugiyama M, et al. Genome-wide association of IL28B with response to pegylated interferon-alpha and ribavirin therapy for chronic hepatitis C. Nat Genet 2009;41:1105-1109.

29. Suppiah V, Moldovan M, Ahlenstiel G, et al. IL28B is associated with response to chronic hepatitis $\mathrm{C}$ interferon-alpha and ribavirin therapy. Nat Genet 2009;41:1100-1104.

30. Rauch A, Kutalik Z, Descombes P, et al; Swiss HIV Cohort Study. Genetic variation in IL28B is associated with chronic hepatitis $\mathrm{C}$ and treatment failure: a genome-wide association study. Gastroenterology 2010;138:1338-1345, 1345.e1-e7.

31. Bibert S, Roger T, Calandra T, et al; Swiss Hepatitis C Cohort Study. IL28B expression depends on a novel TT/-G polymorphism which improves HCV clearance prediction. J Exp Med 2013;210:1109-1116.

32. Ajorloo M, Bamdad T, Hashempour T, et al. Detection of specific antibodies to HCV-ARF/CORE+1 protein in cirrhotic and noncirrhotic patients with hepatitis C: a possible association with progressive fibrosis. Arch Iran Med 2015;18:304-307. 